\title{
Maintaining a network of critical connections over time and space: the case of CARN, the Collaborative Action Research Network
}

\section{Ruth Balogh, Mary McAteer, Una Hanley}

\section{Introduction}

As an open network for action research, CARN supports action research not only in ways that are formally facilitated by its Co-ordinating Group and members, but also in a multiplicity of other, less formal ways, via its members and associates. This chapter provides reflections by members of its current Co-ordinating Group on CARN's history, value system and processes since its foundation in 1976. Our perspective is particular, dealing with issues we consider currently most urgent, coming from our position as co-ordinators and long-standing CARN members. It is also informed by the broader membership's views, canvassed during recent and ongoing conversations through our CARN on the MOVE! project (CARN 2014a, CARN 2015a).

Formally, on behalf of its members, the Co-ordinating Group of seven volunteers maintains a calendar of events embracing an annual international conference taking place alternate years in the UK and elsewhere in Europe, regular Study Days and other events across the world. It also supports structures within the network through an email list and through regional CARN networks in the Netherlands, New Zealand, Norway and Greece; among Spanish, German and (most recently) Portuguese speakers and through a Sponsoring Partnership scheme whereby institutions or partnerships purchase $10 \mathrm{CARN}$ subscriptions over a 3-year period to support local action research.

Publishing action research accounts has been central; initially through the non-peer reviewed CARN Bulletin, (usually connected with CARN conferences and events) which in 1993 evolved into the international peer-reviewed journal Educational Action Research (EAR). In 2006 the nonpeer reviewed Bulletin was re-instated, in order to recognise the value of sharing work-in-progress and to enable conference presenters to publish. Meanwhile, the considerable body of scholarship in the form of books and texts by CARN members, often collaboratively, is too substantial to list.

Since CARN's inception, it has been UK-based, but its reach is global, its annual conference typically welcoming representatives from 6 continents until recent global 'austerity' provoked cutbacks in long-distance travel. Its outline statement positions itself as a network that 'aims to encourage and support action research projects (personal, local, national and international); accessible accounts of action research projects, and contributions to the theory and methodology of action research' (CARN, 2015b). Its identity as an open network is reflected in its practice of 
welcoming action researchers who are not members into its events, including decision-making at the annual conference Steering Group meetings. Asserting such an identity is, however, not straightforward in a world where governance is increasingly associated with formal structures and procedures. Most scholarly associations operate through articles and rules of association, e.g. with elected officers, but CARN has deliberately avoided such formality, and this has been both fruitful and problematic.

Since the mid-1970s the term 'network' has acquired vernacular currency and signifies layers of meanings that ramify in many directions. During that period several technological innovations together created the conditions for the most radical changes in human society and for new relations between capital and labour to emerge. Technological conditions driving the information revolution took place over a matter of years rather than centuries (such as for the agricultural revolution) or decades (for the industrial revolution). The notion of networks is fundamental to understanding the changes we are living in and through (Bell, 2007, Castells, 1996, Kadushin, 2012, Rainie \& Wellman, 2012, Taylor, 2014). Consideration of our evolving network, where even within the relatively confined notion of school networks, led Church (as cited in Black-Hawkins 2008, p.58) to comment that 'confusions and complexities emerge throughout much of the literature'. Church concludes that questions of 'what, or who, is the network?' need constantly to be present.

CARN began as a social network, though not in the sense that this is now understood. 'Social network' signified the desire among its associates to connect in ways that were not necessarily formally organised, connections being maintained through a common interest in exploring teaching and learning practices in schools. Co-ordinated within a UK University, with no formal membership conditions (i.e. no system of fees \& entitlements), connections were maintained through face-toface events, phone calls and paper-based media. The insights from contemporary sociological analysis of social networks allow us to observe that the early network exhibited multiplex characteristics, with multiple relations and flows between network members (Kadushin, 2012, p.37). Thus, for example, certain groups of action researchers formed and animated the network in different ways: Elliott's reflections reveal his own relationships and flows with Austrian and Spanish colleagues in the 1970s, traces of which remain today in the German-speaking and Spanish-speaking CARN networks, and continuing relationships with Australian colleagues (Elliott, 2003, p. 178).

\section{Historical \& philosophical development}

To understand its contemporary position and role, we wish to explore CARN's historical and 
philosophical development. Its early development in the UK is embedded in, and perhaps best articulated through the development and introduction of action research into educational processes. While a number of centres of action research emerged within a few years, it was the work in the early years of the Humanities Curriculum Project (HCP) and the Ford Teaching Project (Ford T) that directly led to CARN's formation.

The years prior to CARN's launch signalled major curriculum development and school change in the UK. Significant events included localised curriculum development projects (such as HCP and the 1972 Raising of School Leaving Age in England and Wales from 15 to 16. The HCP was designed to help humanities teachers address issues of student disengagement, which were about to become exacerbated by the school population expansion. Stenhouse, leading the HCP, was convinced that curriculum development without teacher development was unlikely to lead to sustained change in practice (Stenhouse, 1975). He subscribed to Peters' view (Peters, 1964), that any well-articulated curriculum should take account of, and provide for the 'meshing' of the foundational disciplines of educational theory, namely: philosophy, psychology, sociology and history. Further, these should be seen to 'mesh in with each other in relation to educational policy and practice' (our emphasis) (Peters, 1964, p. 140). Reviewing recent curriculum change, Stenhouse found no such 'mesh' (Stenhouse, 1975, unpaginated foreword): the relationship with practice remained poorly articulated, and only through close study of the curriculum and teaching could the desired 'mesh' be achieved. Suggesting that gaps between aspiration and practice could only be closed by adopting a 'research and development approach to one's own teaching' (ibid, p3), he laid the foundations for an approach to teacher research with both a theoretical and practical conceptualisation, incorporated in and expressed through the intention to improve.

For many teachers, Stenhouse's thinking represented a significant paradigm shift in repositioning the teacher as someone who enabled mediation, rather than delivery, of a curriculum which became conceptualised as processes, rather than subject knowledge and content. The need for teachers to experiment in practice in order to develop well-justified pedagogical practices also marked a significant shift in the positioning of the classroom teacher. Thus, the HCP itself was seen by many as the first real teacher research project undertaken in schools. Teachers were encouraged to use inquiry and discussion based practices in order to develop 'a set of principles to guide teachers in translating educational aims into concrete pedagogical practices', or 'praxiology' in Elliott's terms (Elliott, 199, p.15).

HCP research was conceptualised in two ways: that carried out by the teachers/practitioners 
themselves, as insiders in the process, first order inquiry, and that undertaken by the (outsider) university research team, second order inquiry. Though many considered Stenhouse's idea of teachers undertaking research into their own practice somewhat radical, he also argued for support and guidance by professional researchers who would also choose research focus (Stenhouse, 1975). In practice, these researchers were university lecturers in education, but Stenhouse insisted that 'first, teachers must be intimately involved in the research process; and second, researchers must justify themselves to practitioners, not practitioners to researchers' (Stenhouse, 1985, p 19.)

While this represented a significant departure from the 'outsider' researcher concept, it still, in practice, implied academic hierarchy and control. Elliott talks of challenges for the central team in facilitating rather than manipulating teacher reflections (1991, p. 27); yet it was through this that the concept emerged of teachers choosing their own research focus and generating their own explanatory and action hypotheses. Drawing on Lewin and Corey, Stenhouse believed that action research, initially used as a form of 'research on the conditions and effects of various forms of social action and research leading to social action' (Lewin, 1946, p. 35), was an appropriate and powerful way to explore and articulate relationships between 'the curriculum' and 'teaching'.

Elliott articulated Stenhouse's work to further emphasise the classroom teacher's role over the research focus and its undertaking. His work on Ford T offered an enquiry learning approach into science teaching with both teachers and pupils considered learners. Thanks to a small grant from the Ford Foundation to support action research into this discovery learning approach, Elliott with Clem Adelman and a number of international colleagues, launched the Classroom Action Research Network (CARN) in 1976, signalling an intent 'to radically reconstruct educational research by making teachers' investigations of classroom practice its central component.' (Somekh, 2010, p. 109). The network's purpose was to provide a forum for testing ideas about teaching between peers, deliberately departing from 'power-coercive' approaches to academic research in education. The location of CARN in the University of East Anglia Centre for Applied Research in Education (CARE), subsequently part of the university School of Education, helped bring action research to the attention of teacher educators. The impact of this was far reaching. Within a decade, UK universities were incorporating action research and reflective practice into both initial teacher education programmes and master's degrees.

This early history is important since it demonstrates the process through which CARN came into being, and also reveals the underlying values it espoused then and now. Early publications reveal a network where action research could be both educative and educational, underpinned by an 
epistemology where the theory-practice relationship was reconceptualised as democratic rather than hierarchical. Teachers engaged in collaborative action research with both colleagues and pupils (Stenhouse, 1980). The cyclical and reciprocal interactions between research and findings, between action and theory, and between researcher and co-researcher(s) were understood not only as bringing about democracy, but as being 'an embodiment of democratic principles in research', (Carr and Kemmis, 1986. P. 164).

Winter articulated reflection as the critical process that allows both action and research their authenticity in retheorising action or practice as research, and research as practice or action. ... the theoretical necessity of a reflexive conception of research's relation to action, so that their relationship may be theorised in ways which preserves the authenticity of both, i.e. which preserves research's capacity for achieving a critical distance from action, AND preserves action's intelligibility, as a creative, rather than a causally determined response to interpretive meaning.

(Winter 1987: 22)

Thus, teachers (and other practitioners) became generators of knowledge, and constructors of its mediation in practice.

\section{CARN's extension into new settings}

CARN's articulation of action research within the academy attracted the attention of other professions, and network members were approached in the late 1980s by health and other professional practitioners to support their action research. Inevitably, the word 'Classroom' in the network name became a subject of debate. Somekh (2010) documents the difficulties that replacing 'Classroom' with 'Collaborative' -caused for many members, Elliott included, who were concerned about moving from CARN's educational valuebase. But it was agreed that this renaming was necessary to signal the inclusiveness of CARN, with Somekh arguing for the centrality of learning in action research: "the action researcher is always engaged in an educative process' thus being simultaneously 'learner and teacher, co-constructing knowledge with other participants" (p. 104).

This change supported multiple growth-points in action research in the 1980s among health and social care practitioners. In nursing, action research was emerging as a means to facilitate change in nursing practices (Greenwood, 1984; Webb, 1990; Titchen \& Binnie, 1993). Nursing was professionalising; it sought its own distinctive knowledge base, and empiricist research approaches 
to implementing change had met with limited success. The concerns of nursing practice were argued within EAR as being similar to those of teaching and education (Meyer, 1993). In the UK, the nurse tutor career path required higher qualifications in education and nurses encountered action research through these learning experiences. New hospital ward-based clinical teacher roles opened the hospital setting as a site of inquiry into practice (Titchen \& Binnie, 1993). Donald Schön's ideas on reflective practice were influential (Schön, 1983), as were the ideas of new paradigm inquiry (Reason, 1988). Where these ideas took root, they offered a new approach to issues of practice, theory and learning that became the principal pre-occupations of the first UK nursing $\mathrm{PhD}$ studies, offering a practice epistemology based on reflection-in-action rather than technical rationality (Meyer, 1993, p. 1067).

Action research was also emerging in UK health settings where social care predominated and from which the technico-rational gaze of medical research was averted. Not only were service users stigmatised or marginalised in such services, but the services themselves had lower professional status than more medicalised disciplines with their greater technical and practical enactment of biomedical scientific knowledge. Action research studies were reported in mental health (Towell \& Harries, 1979), learning disability (Munn-Giddings, 1993) and in care of older people (Hart \& Bond, 1995; Smith \& Cantley, 1985). At this time in the UK the process of closing down long-stay institutions was beginning, with their occupants re-settled into 'the community'. Where action research was undertaken to enable and inform this process, the aim of giving service users a greater voice was an important and challenging element, and the literature on action research in community development within the UK, and development policy beyond it, informed the thinking and methods used (Hart \& Bond, 1995, p. 124; Munn-Giddings, 1993). Echoing this client focus, action research in hospital settings was used to introduce person-centered or 'primary' nursing (Titchen \& Binnie, 1993). Crossing all these fields was an undercurrent of reference to feminist research, with its particular challenge to positivism through the re-positioning of relationships between researchers and 'the researched' to encompass the idea that empathy between persons could enter the frame and be openly discussed, instead of being removed from it (see, eg. Oakley, 1981).

The collaboration between CARN members and health and social care practitioners in the UK resulted in a conference at Keele University UK in 2001. This became a biennial event, with CARN involvement, and an important forum for an emerging movement of practice development among nurses, and eventually the International Practice Development Collaborative (IPDC), which now has its own journal (IPDC, 2015). The participation of IPDC members in CARN Conferences and CARN members in IPDC Enhancing Practice Conferences, provided a communicative space for 
sharing practice and mutual learning about participatory practice, in hosting conferences. The constraints on such practice are considerable, especially over timetabling. One important practice shared between both conferences is for the programme to include daily 'host' or 'home' groups, for the same people, thus providing a welcoming forum for new participants and a thread for pursuing discussion - which have sometimes focused on particular issues - enabling 'layers' of understanding to be explored. The flow of learning has been two-way, the 'host' group practice having originated with CARN. In the other direction, CARN has drawn on IPDC practice where enabling creative approaches towards research had flourished better. Despite CARN encouragement otherwise, conventional didactic practice had become surprisingly prevalent at CARN conferences, so, inspired by IPDC, CARN held a workshop which generated guidelines for enabling presenters to work more interactively and creatively (CARN 2011).

\section{Being a network}

The question of 'what, or who, is the network' challenges us to consider what the term signifies for CARN. Kelly (1995) offers a starting point regarding the concept of networks generally: that 'the only [type of] organization capable of non-prejudiced growth, or unguided learning is a network. All other topologies limit what can happen....the network is the least structured organization that can be said to have any structure at all' (Kelly, 1995, p. 25). As previously argued, the minimal social and informational structure of CARN must be understood as part of the less visible structures that are performed within and around it.

The history of CARN shows how the academy has gradually disengaged from resourcing its activities, reflecting the ascendency of marketization and values of commercial 'success' over values of scholarship in higher education (Ball, 2007; Brown, 2013; McGettigan, 2012). Having originated as an extension of a major research project, CARN retained support from its initial academic base, and even when this became no longer feasible, support was still forthcoming from UK higher education institutions. This support, usually linked to research funds, was minimal but valuable, consisting of provision, often without charge, of venues for meeting and certain travel expenses. But support for the co-ordinating function became less forthcoming and in 2002/3 this contributed to a financial crisis that threatened the network's viability. A way forward was needed that would secure its finances. After extensive debate of a proposal to spread the co-ordination and initiate schemes to sustain its finances, a new Co-ordinating Group of six was established as a partnership between Manchester Metropolitan University and St Martin's College Cumbria, with the secretariat at Manchester. Somekh describes the new arrangements as ones which "arose from a contradiction between a voluntaristic, inclusive ethic and what seemed at the time, a surrender to 
oppressive market forces," adding that while they constituted "a move towards more structure and financial accountability, [they] have proved to be creative and empowering" (Somekh, 2010, p. 115).

The ability of a network to survive when it relies for its income entirely on low (and thus inclusive) membership fees is evidence of a certain resilience. The reconfiguring of its co-ordination took place via discussion among members over electronic mail and a steering group meeting. These discussions showed the network remained highly valued, and its co-ordination function was redistributed. There were no formal appointment procedures for these new arrangements as a constituted organisation would have required, although they were loosely formalised within the two universities as being led in each by two prominent action researchers, Marion Dadds \& Bridget Somekh. Yet the decision was made in as democratic a way as such issues can be. The minimal structure of a network appeared to be effective in keeping it active. It remains debateable whether a stronger structure with formal positions and procedures for recruitment would have succeeded in finding the people needed to undertake the network's co-ordination.

Central to these new arrangements were the Sponsoring Partnership scheme, which offered CARN's supporters a means to secure its finances, and Study Days which enabled regular CARN meetings (Balogh 2007). The Co-ordinating Group also raised the membership fees, included an entitlement to receive the journal EAR and undertook to ensure the annual conference would at least break even financially. Governance structures remained light and relatively open, though slightly more elaborated through a partial division of roles whereby Co-ordinating Group members took specific responsibilities for the increased range of CARN activities. In the absence of formalised structures and procedures for the responsible oversight of CARN activities, the network's statement of its values (CARN 2015b) remains the only publicly accepted reference point for guidance when potentially contentious decisions have arisen. The significance of this statement has thus been far greater than is generally the case for entities like mission statements which are rarely embedded into institutional practice.

Resources to support the Coordinating Group's work in its early years were provided by the partner institutions. Little of such support remains available today from any higher education institution, not just in the UK but in many other countries. Practitioners outside higher education have never been well supported to engage in network activities. The naming of one-day CARN events as Study Days was specifically chosen to enable health care practitioners to obtain support for professional development, and such perspectives enlivened the Study Day programme (Balogh, 2007). But 
across its disciplines, the profile of CARN membership has shifted towards stronger connections to higher education, with practitioners tending to be postgraduate students.

CARN's cultural practices continue to aspire to a collaborative ethos; it welcomes "contributions from a wide range of philosophical perspectives which offer the ability to unsettle discourses that divide theory from practice, and to elaborate their interlinkage"' (Balogh \& Springett, 2014). The following analysis of the Study Day scheme is an example of such practices, and shows how CARN has facilitated local action research, where recent cycles of policy change across the world have significantly increased the challenge faced by practitioners in their own work places and practice.

\section{Study Days as sites for network development in contemporary times}

Study Days can be held by any practitioners and/or academics who share the beliefs and values of action research as a practitioner or user led activity which seeks to improve practice and is concerned with developing the critical dimensions of reflection and reflexivity. The incidence and history of Study Days have been documented by Balogh (2007) and Rowell, Inoue and Getz (2014). Over the past twelve years the balance between UK and non-UK Study Days has changed. Initially UK Study days averaged 3 per year, recently settling annually at one or two. Those held outside the UK have increased from one annually to three or four per year, reflecting continuing support world wide for action research. Venues have included the Antipodes, Sri Lanka, South Africa, USA, Canada, and in Europe: Holland, Norway, Denmark, Spain, Austria, Finland, Greece, Ireland and Scotland.

Any member can request support for a Study Day. It follows, that given the diversity of situations and places, they have taken various forms as organizers have responded to local conditions and interests. CARN contributes towards costs on the basis that local institutions might provide a physical space cheaply, though the communicative space is not intended to be 'institutional'. In the UK, but increasingly elsewhere, both space and time in academic institutions have become highly regularized as both practitioners and academics are micro-managed into increasing rounds of educational and social policy change, accompanied by reduced budgets. Culturally, the values that had supported action research and CARN, have been eroded, to make way for those with a significant neo-liberal flavour. Focus has shifted to 'value for money' and an accountability system that focuses on technical efficiency and effectiveness in these terms, coined 'economy of performance' (Stronach et al, 2002). Action research has not been immune to this: Kemmis (2006, p. 459) argues "some action research today lacks a critical edge." Both he and Carr noted the rise of 
technical as opposed to critical approaches to action research together with the use of action research by "Western governments and school systems to control Schooling" (Somekh \& Zeichner, 2008, p.5) These shifts in focus impeded the telling of 'unwelcome truths' (Kemmis, p.459), with an associated shift toward 'domesticating' those involved into prevailing policy conventions.

Conferences are a site for annual exchanges; Study Days promote more frequent, local forums where 'the flows of knowledge' can be examined and enriched by local activity. While "The CARN Community has developed what Wenger (1998, p. 73) calls 'a shared repertoire of actions, stories, discourses and concepts" (Somekh, 2010, p. 115), there are also differences and diversity which need to be acknowledged, celebrated and critiqued. Those who come together do not always agree and have varying beliefs and expectations about their practices and what counts as valuable research. However, such differences do not necessarily need to be smoothed out, but recognised something more easily managed when understandings and beliefs about the value of the tasks being undertaken in specific contexts are shared, and where exchanges are respectful (Rowell et al, 2014). Rowell and colleagues recall the lived experience of a Study Day with the evocative metaphor of 'motion sickness', as they sought to manage the many anticipated and unanticipated moments in bringing together practitioners from diverse settings to develop a critical dialogue.

Study Days are thus sites for setting challenges as well as developing trust. As Somekh and Zeichner (2009) suggest, "By sharing knowledge and experiences of action research - not just between East and West, but between action researchers in many countries and cultures - it is possible to contribute to the "world of flows' knowledge and learning from multiple local sites," (p. 18) including ideas for locally based reform, and contributing to Appadurai's notion of 'globalization from below' (Appadurai 2013). The most recent Study Days have extended significantly beyond the confines of local meetings by sharing video-taped extracts from their local deliberations online (CARN 2015c). These initiatives have arisen not only from Study Day organisers, but also in response to requests from CARN members elsewhere in the world wanting to connect to local knowledge generation. Such virtual links offer new potential for the network's activities to proliferate globally from below.

\section{CARN on the MOVE!}

The effects on network activities and on the 'lifeworld' experiences (Kemmis 2010) of the CARN Co-ordinating Group members themselves, of economic 'austerity' and the rapid development of computer mediated communication (CMC) - both global phenomena - prompted the Group in 2013 to initiate an action research project termed 'CARN on the MOVE!' to consult with its members 
and other action researchers about how to respond to these challenges (CARN, 2014a; CARN, 2015a). It aimed to 'uncover, recover and discover new directions, connections and intersections that will promote Action Research in and across a growing range of communities of practice both in the UK and internationally' (CARN 2014b), using a process that it was hoped would 'animate' the network (Boud \& Miller, 1997, Dewar and Sharp, 2013 p. 7).

We did this in two phases. Initially the Lead Co-ordinator (RB) engaged in several in-depth conversations with any CARN member who wished to respond to a Briefing Paper setting out the Co-ordinating Group's concerns (CARN 2014b), at the same time taking any actions on suggestions that could be implemented immediately; and reported on these and the conversations to the membership and the CARN Co-ordinating Group (CARN 2014a). In the second phase, ideas and proposals arising from the first phase were further discussed by telephone in meetings of a specially constituted Virtual Spaces Group; through an online survey; within the CARN Co-ordinating Group; and at the CARN 2014 Conference. This project attracted involvement from many parts of the world, from long-standing and new members, and a wide disciplinary base. It successfully animated at least some parts and nodes of the network, and confirmed that members were experiencing similar difficulties world-wide from austerity policies. We acted on most of the ideas proposed to us, including regularising our support for regional groups, deepening and extending our links with other international action research networks, extending the use of languages other than English within CARN Forums, and devising methods to support special and sectional interests. Some are still in process at the time of writing, including the crucial issue of developing CARN's virtual presence and facilities for internet-based discussions. The project also energised the Coordinating Group to support action research in new directions, recruiting new members, and provoking fresh thinking about how to continue to function as a network in the new environment. An important feature of the comments made about the way people value CARN concerned its 'openness' in the widest sense, for example :

'being open, honest and critical in a positive, appreciative, encouraging way' 'maintain the open feeling - it is very welcoming' 'CARN gives the opportunity to participate freely and democratically in an open environment' (CARN 2015a)

Such statements indicate the richness of how our aspiration to 'openness' is understood, and pose particular challenges for CARN's practice in virtual spaces, understanding as we do that the production of knowledge is itself a social act. Thus as action researchers we are profoundly interested in the way that encounters are socially situated, and the 'openness' of the network is 
intended to reflect this interest as a legitimate and necessary object of inquiry. From its inception, action research has privileged the value of personal encounter, particularly within groups, and the group has been a fundamental vehicle for simultaneously exploring issues, engendering learning, and creating social conditions for agency (Lewin, 1946, Marrow, 1969, Hart and Bond, 1995, Coghlan and Brannick, 2003, Somekh, 2006). But face-to-face groups are now only one kind of possible social situation for people to meet, and while new possibilities emerge from what Bakardjieva describes as a new kind of 'immobile socialisation' (Bakardjieva, 2007), the conditions for agency among virtual communities are different.

Since the practice of action research is its chief problematic, as are questions of values, ethics and virtues (McNiff, 2015, Elliott, 2015) - in the same way that our 'daily life is enmeshed in moral lines of discrimination' (Goffman, 1959, p. 242) - it seems to us that the particular ways that online social encounters may constrain or liberate need to be explored, as do the prevailing ethics, values and power relations of virtual spaces. If we examine these ethics, we can see how they have changed during the development and growth of the Internet and the world-wide web. From their beginnings as networks of 'utopian, communal and libertarian undercurrents ' (Castells, 1996, p. 357), they now reflect and even amplify the inequalities of the offline world. In the last few years, email platforms have become dominated by Microsoft, Google, Yahoo! and a handful of other huge telecommunications providers, which along with other Internet companies like Amazon, Youtube, Facebook and eBay now broker to advertisers information that they mine from every individual act of online useage. Moreover, the online gateways through which these data are obtained cannot be avoided, so that it is almost impossible for Internet users to find spaces where they are not at the same time labourers and consumers on behalf of a massive advertising industry (Taylor, 2014). Furthermore, it has become an industry that operates according to an intrusive ethical code not tolerated previously in broadcast media, at least in the US and UK. No regulation via sponsorship laws nor for public broadcasting requirements exist online as they do for US and UK broadcast media (Taylor, 2014). Of particular interest to academics is the way that bibliographic search engines display, and therefore privilege, texts that are both recent and frequently cited, rendering the foundational work in all disciplines less visible than the current and the popular (Evans, 2008).

We therefore need to understand cyberspace as offering further opportunity to develop 'participatory practice in a non-participatory world' (Ledwith and Springett, 2010). The new context we find - of austerity, a more global membership seeking different kinds of engagement, the opportunities and demands of CMC and the effects of these on our relationships with other action researchers around the world - represent for us not just a new background but a new multiplex of networks and 
lifeworlds within which we need to explore, understand and develop our practice; we are already not separate from them. Our repertoire of skills for respectful engagement, which some identify as a new paradigm of inquiry (Heron, 2010) provide affordances for realising new kinds of encounter, and what we have to offer in these changed times may even open new ways of working to others beyond our practicum. However, CARN members and supporters still affirm the importance of face-to-face encounter (CARN 2015a) and see CMC as offering extensions to this, not displacement. The central questions for an emerging order for our network revolve around ethically framed enquiry about what kinds of public / virtual space we wish to develop or otherwise engage in, and how.

\section{Conclusion}

We have tried to describe some of the problems encountered in maintaining CARN's identity and modus operandi as an open network over its 40-year history. Our perspective has derived from our role in co-ordinating the network in recent years, further informed by the views of members through our 'CARN on the MOVE!' consultation. Reflecting on its history prior to our involvement in coordinating the network has become an important means of helping us collaboratively to understand and thus develop our practice. Similarly, trying to appreciate what it means to be an academic network in the digital age, under conditions of globalised connections also provides new insights.

The new kinds of public space provided by online connections impose a new hegemony with new and sometimes confusing values, and Somekh's tension between a "voluntarist inclusive ethic and oppressive market forces" (Somekh, 2010, p. 115) remains. The combination of austerity policies with increasing reliance on CMC is closing down many of the inter-personal encounters via reflective spaces that are so essential to processes of collectively thoughtful action. The networked individualism of the online world has been liberating in some respects, and has enabled new types of encounter and connection, but its appeal has also masked the hegemony of dominant internet businesses which not only reproduce but amplify offline inequalities. Critiques such as Taylor's (2014) provide us with the beginnings of a critical perspective on how, as consumers, internet users are labouring in the interests of advertising giants to provide, via consent processes which are nonnegotiable, data to enable them to re-cast us in the eyes of vendors. If, as Ball (2007) contends, privatisation of public life is also changing 'who we are and what we do, what it means to be a teacher and a learner ... [and] encouraging competitive individualism and instrumentality' (p. 188) we have travelled far from the early days of CARN where a project critiquing objectives-based curricula could be supported by a major American business-linked interest such as the Ford Foundation. We may also have travelled from CARN's identity claim as an 'open network' - easily 
sustained when it had limited capacity for publicising its activities and relying on the enthusiasm of scholars for recruiting interest. The nature of online 'public' space now available needs to be understood in terms of the values that are already supported by its infrastructure, and which will influence the way that the network maintains its 'openness'.

We are beginning to explore the many potential interactions between online and offline lives for the purposes of exploring action research. The 'globalisation from below' of CARN's expanding Study Day programme indicates the enduring thirst for human encounters, while the demand for online links to these shows an enthusiasm for developing new kinds of dialogue via both $\mathrm{CMC}$ and live conversation. Such matters must also play a key role in our developing relationships with other action research networks internationally. If reflecting upon, and analysing our history and practice offers the best chance of dealing with such issues, then perhaps we and our colleagues around the world will be adequately equipped to do so.

\section{References}

Appadurai. A. (2013) The Future as Cultural Fact: Essays on the Global Condition. London: Verso Ball, S. J. (2007). Education plc: Understanding Private Sector Participation in Public Sector Education. London: Routledge.

Balogh, R. (2006, November) CARN Study Days studied: reflections on collaboration in the CARN Study Day Programme 2003. - Keynote presented at CARN Conference Nottingham UK Retrieved from http://www.esri.mmu.ac.uk/carnnew/conferences.php

Balogh, R. and Springett, J. (2014). Collaborative Action Research Network. In D. Coghlan and M. Brydon-Miller (Eds.). The Sage Encyclopaedia of Action Research (pp. 119 - 120) London: Sage Publications.

Bakardjieva, M. (2007). Virtual Togetherness: An everyday life Perspective. In D. Bell and B. Kennedy (Eds) The Cybercultures Reader ( $2^{\text {nd }}$. ed. pp ,236 - 253) London: Routledge.

Bell, D. (2007). Introduction to Cybercommunities. In D. Bell and B. Kennedy (Eds) The Cybercultures Reader $\left(2^{\text {nd }}\right.$. ed. pp ,186 - 190) London: Routledge.

Black-Hawkins, K. (2008). Networking Schools. In C McLaughlin, K Black-Hawkins and D McIntyre with A Townsend (Eds.) Networking Practitioner Research (pp. 57 - 82).

London: Routledge.

Boud, D. and Miller, N. (Eds.) (1997). Working with Experience: Animating Learning. London: Routledge 
Brown, R. with Carasso, H. (2013). Everything for Sale? The marketisation of UK higher education Abingdon OXON: Routledge

Carr, W. and Kemmis, S. (1986). Becoming Critical: Education, Knowledge and Action Research. London: The Falmer Press.

Castells, M. (1996) The Information Age: Economy, Society and Culture, Volume 1:The rise of the Network Society. London: Blackwell.

Coghlan, D. and Brannick, T. (2003) Kurt Lewin: the 'Practical Theorist' for the $21^{\text {st }}$ century The Irish Journal of Management 24 (2) 31-37.

Collaborative Action Research Network (2011) Conference narratives: Planting a seed not a flower. Retrieved from http://www.esri.mmu.ac.uk/carnnew/resources.php

Collaborative Action Research Network (2014a) CARN on the MOVE! Interim report for CARN membership Retrieved from http://www.esri.mmu.ac.uk/carnnew/activities/COTMreportsept14.pdf

Collaborative Action Research Network (2014b.) CARN on the MOVE! Briefing Collaborative Action Research Network February 2014

Collaborative Action Research Network (2015a) CARN on the MOVE! Final report Retrieved from http://www.esri.mmu.ac.uk/carnnew/activities/COTMreport.pdf

Collaborative Action Research Network (2015b) An Outline Statement Retrieved from http://www.esri.mmu.ac.uk/carnnew/

Collaborative Action Research Network (2015c) Study Days Retrieved from http://www.esri.mmu.ac.uk/carnnew/study.php

Dewar, B. and Sharp, C. (2013). Appreciative dialogue for co-facilitation in action research and practice development International Practice Development Journal 3 (2) 1-10

Elliott, J. (1993). Action Research for Educational Change .Milton Keynes: Open University Press.

Elliott, J. (2003). Interview with John Elliott 6 December 2002. Educational Action Research 11(2) 169-180.

Elliott, J. (2015). Educational action research as the quest for virtue in teaching. Educational Action Research, 23(1) 4-21.

Evans, J. (2008, July 18). Electronic Publication and the Narrowing of Science and Scholarship. Science, p 99

Greenwood, J. (1984). Nursing Research: a position paper. Journal of Advanced Nursing, 9 77-82.

Goffman, E. (1969). The Presentation of Self in Everyday Life Penguin Books: Harmondsworth Middlesex

Hart, E. and Bond, M. (1995). Action research for health and social care: a guide to practice. Buckingham: Open University Press. 
Heron, J. (1996). Co-operative Inquiry. London: Sage

International Practice Development Collaborative. (2015) Retrieved from

http://www.science.ulster.ac.uk/inhr/pcp/ipdc.php

Kadushin, C. (2012). Understanding Social Networks: theories concepts, findings. Oxford: Blackwell.

Kelly, K. (1995). Out of Control: the Rise of Neo-biological Civilisation. Menlo Park CA: Addison Wesley.

Kemmis, S. (2001). The 2000 Radford Lecture: Educational Research and Evaluation: Opening Communicative Space. Australian Educational Researcher 28 (1) 1-30

Kemmis, S. (2006). Participatory action research and the public sphere. Educational Action Research, 14(4) 459-476.

Kemmis, S. (2010). Exploring the relevance of critical theory for action research: Emancipatory action research in the footsteps of Jurgen Habermas. In P. Reason and H. Bradbury (Eds.) The Handbook of Action Research Concise Paperback edition (pp. 94-105). London: Sage Publications.

Ledwith, M. and Springett, J. (2010). Participatory Practice: Community based action for transformative change. Bristol: Polity Press.

Lewin, K. (1946). Action Research and Minority Problems. The Journal of Social Issues 234 - 46

Marrow, A.J. (1969). The Practical Theorist: The Life and Work of Kurt Lewin New York and London: Basic Books

McGettigan, A. (2012). The Great University Gamble. London: Pluto Press.

McNiff, J. (2015). Editorial Special Issue: Value and Virtue in Practice-based Research.

Educational Action Research, 23 (1) 1-3.

Meyer, J. E. (1993) New paradigm research in practice; the trials and tribulations of action research. Journal of Advanced Nursing, 18(7) 1066-1072.

Munn-Giddings, C. (1993). 'A different way of knowing': social care values, practitioner research and action research. Educational Action Research, 1(2) 275-285.

Oakley, A. (1981). Interviewing Women: a contradiction in terms. In H. Roberts (Ed.) Doing Feminist Research (pp. 30 - 59). London: Routledge and Kegan Paul.

Rainie, H. and Wellman, B. (2012). Networked: the new social operating system. Cambridge MASS MIT Press

Reason, P. (1988). (Ed.) Human Enquiry in Action: Developments in New Paradigm Research. London: Sage.

Rowell, L., Inoue, N. and Getz, C. (2014). Reflective practice and motion sickness: Thoughts on the 
first North American Action Research Study Day. Educational Action Research, 22(2) 251-269.

Schon, D. A. (1983). The Reflective Practitioner. New York: Basic Books.

Smith, G. and Cantley, C. (1985). Assessing Health Care: a Study in Organisational Evaluation. Milton Keynes: Open University Press.

Somekh, B. (2006). Action Research a methodology for change and development. Maidenhead: Open University Press.

Somekh, B. (2010). The Collaborative Action Research Network: 30 years of agency in developing educational action research. Educational Action Research, 18 (1) 103-121.

Somekh, B. and Zeichner, K. (2009). Action research for educational reform: remodeling action research theories and practices in local contexts. Educational Action Research, 17 (1) 5-21.

Stenhouse, L. (1975). An Introduction to Curriculum Research and Development.

London: Heinemann.

Stenhouse, L. (Ed) (1980). Curriculum research and Development in Action. London:

Heinemann.

Stenhouse, L. (1985). What counts as research. In J. Rudduck and D. Hopkins Research as a Basis for Teaching (pp. 8-19) Heinemann Educational Books: London \& Portsmouth.

Stronach, I., Corbin, B., McNamara O., Stark, S., and T. Warne, (2002). Towards an uncertain politics of professionalism: teacher and nurse identities in flux. Journal of Education Policy, 17 (1) 109-138.

Taylor, A. (2014). The People's Platform: Taking Back Power and Culture in the Digital Age. London: Fourth Estate.

Titchen, A. and Binnie, A. (1993). Research Partnerships: collaborative action research in nursing. Journal of Advanced Nursing. 18 858-865

Webb, C. (1989). Action research: philosophy, methods and personal experiences Journal of Advanced Nursing, 14 403- 410.

Wenger, E. (1998). Communities of practice: Learning, meaning and identity. Cambridge: Cambridge University Press.

Winter, R. (1987). Action Research and the Nature of Social Inquiry: Professional Innovation and Educational Work. Avebury: Aldershot. 
